\title{
The missing element: consanguinity as a component of genetic risk assessment
}

\author{
Michelle Bishop, BSc, Grad Dip Gen Couns ${ }^{1,2}$, Sylvia Metcalfe, PhD, ${ }^{1,2}$ and Clara Gaff, PhD ${ }^{3,4}$
}

\begin{abstract}
Purpose: There are no clinical practice data regarding collecting information on consanguinity as part of family history, despite its relevance for identifying at-risk pregnancies. We determined current practice and influencing factors in documenting consanguinity as part of pregnancy assessment by midwives, key health professionals in socialized medicine. Methods: Data were gathered from midwives in Victoria, Australia, which contains an ethnically heterogeneous population. Current practice and issues influencing practice including frequency of enquiry and attitudes regarding collecting consanguinity and family history information were documented. Results: Family history is collected by midwives, but is restricted to medical information only. Although $65.1 \%$ of midwives collect family history, only $6.4 \%$ ask about consanguinity. Direct questioning about consanguinity was seen to be difficult, reflecting social taboos, with discussion usually prompted by patient disclosure. The factor significantly associated with clinical practice in multivariate analysis was midwives' lack of confidence (adjusted odds ratio: 5.3 [95\% confidence interval 1.3-22.1]) in discussing consanguinity. Conclusions: Organizational and social barriers prevent collecting information about consanguinity in midwifery practice, restricting identification of at-risk pregnancies. Change theory is applied to inform strategies to enhance the identification of consanguineous couples.
\end{abstract}

Genet Med 2008:10(8):612-620.

Key Words: consanguinity, family history, prenatal, midwifery, primary care

Accurate assessment of a patient's genetic risk through the collation of family history has been identified as a key skill for the primary care practitioner as a means to assess risk and identify candidates for genetic testing. ${ }^{1-5}$ Considerable effort has been expended in the development of family history collection tools, such as those from the American Medical Association, the March of Dimes and The U.S. Surgeon General's Family History Initiative, to facilitate this process. ${ }^{6-8}$ Although it is common practice for primary care practitioners to document information about the health of family members, ${ }^{9-11}$ Bennett argues that information should be collected beyond the conventional "family medical history", advocating for the inclusion of ethnicity and consanguineous relationships as crucial components of accurate genetic risk assessment. ${ }^{12}$ The collection of this information during the prenatal period has been supported in theory ${ }^{2}$ and present in both the American Medical Association and March of Dimes prenatal family his-

\footnotetext{
From ${ }^{1}$ Genetics Education and Health Research, Murdoch Childrens Research Institute, Melbourne, Australia; ${ }^{2}$ Department of Paediatrics, The University of Melbourne, Melbourne, Australia; ${ }^{3}$ Genetic Health Services Victoria, Melbourne, Australia; ${ }^{4}$ Institute of Medical Genetics, Cardiff, United Kingdom.

Clara Gaff, PhD, Genetic Health Services Victoria, 10th floor, Royal Children's Hospital, Flemington Road, Parkville 3052, Victoria, Australia.E-mail: clara.gaff@ghsv.org.au

Disclosure: The authors declare no conflict of interest.

Submitted for publication November 28, 2007.

Accepted for publication April 18, 2008.

DOI: $10.1097 / G I M .0 b 013 e 31817 d 2 a 65$
}

tory tools. ${ }^{6,7}$ Although ethnicity information is collected when relevant for genetic risk assessment, ${ }^{13,14}$ the extent to which information about consanguinity is incorporated into prenatal risk assessment by primary care practitioners is not known.

By convention, consanguineous relationships are defined as couples that are related as second cousins (fifth-degree relatives) or closer. Although marriages in North America, most of Europe and Australia are not typically consanguineous $(<1 \%),{ }^{15}$ there are populations within these countries with higher rates of consanguinity. This is due to migration from areas such as Africa, Middle East, and South East Asia where the rate of consanguinity is between $20 \%$ and $50 \% .{ }^{16}$ However, these consanguineous unions are not confined to particular religious segregates or cultures.

Offspring of consanguineous unions are at increased risk for birth defects with the figure quoted for first cousin unions (third-degree relatives) of 1.7-2.8\% above the background risk. ${ }^{16}$ This is primarily due to autosomal recessive mutations inherited from a common ancestor, ${ }^{16}$ but also includes disorders of putative multifactorial and complex inheritance such as congenital heart defects. ${ }^{17,18}$ Newborns are also more likely to have decreased birth weight ${ }^{19}$ and present with apnea of prematurity ${ }^{20}$ than newborns whose parents are not consanguineous. Consanguineous pregnancies are also at a higher risk for adverse outcomes such as miscarriages, still births, and infant death. ${ }^{21-25}$ The National Society of Genetic Counselors has published recommendations for the screening of consanguineous couples and their offspring. ${ }^{16}$ Although these recommen- 
dations do not suggest genetic testing on the basis of consanguinity alone, the collection of a comprehensive family medical assessment is advised. ${ }^{16}$ Carrier testing can then be offered based on the family history, and ethnic background. ${ }^{16,26}$ Primary care practitioners are in a key position to identify consanguineous couples and facilitate subsequent genetic screening. ${ }^{26}$

Although primary care practitioners are expected to collect information about family history, including consanguinity, their perception of this role and any beliefs, barriers or factors influencing practice are not known. Increasingly midwives and certified nurse-midwives in many Western countries are providing a broad spectrum of maternity care, often working alongside obstetricians, general practitioners or family physicians. ${ }^{27-30}$ Many hospitals are also encouraging midwives and certified nurse-midwives to work autonomously when providing prenatal care, a trend that has been observed internationally despite the differences in organized health care structures between different countries. ${ }^{27,31-33}$ As nothing is currently known about how midwives collect family history or their attitudes around asking about consanguinity, we have explored both current practice and attitudes toward collecting this information within an ethnically heterogeneous population. As part of a larger study investigating midwife practice in genetics, we determined frequency of enquiry, and which factors influence midwives' role. We identify a number of barriers to raising the issue of consanguinity, which may be overcome through practical measures.

\section{METHODS}

\section{Health system}

Maternity care in Australia is offered in both private and socialized medicine, with $64 \%$ of women in Victoria giving birth in a public hospital in 2004, and 36\% having private care during pregnancy and postpartum period ${ }^{34}$ (for specific information see www.health.vic.gov.au/maternity). Genetic services provided by medical geneticists and genetic counselors are available in three metropolitan tertiary referral centers.

\section{Data collection}

We adopted a two phase approach to data collection, which occurred between July 2005 and March 2007. Ethics approval was obtained from relevant Human Research Ethics Committees for each phase of the study.

\section{Phase 1}

Focus groups were used to collect data to allow discussion and debate between participants and in-depth exploration of organizational practices. ${ }^{35}$ A purposive sample of midwives was recruited via direct contact with midwifery and maternity service managers at six public and one private maternity hospital. Hospitals were specifically targeted to represent the range of maternity services available in Victoria. Focus groups were structured to include only midwives working within the same organization, to permit participants to share experiences and practices unique to their hospital. Discussion about family his- tory and consanguinity were prompted by the facilitator (MB) if not raised spontaneously by participants. All focus groups were audiotaped and transcribed verbatim. Thematic analysis of the focus group transcripts was conducted using a constant comparison approach. ${ }^{36}$ Analysis of transcripts was performed independently by two researchers (MB and SM) for coding reliability. NVivo 7 (QSR International Pty Ltd, Melbourne, Australia) was used for data management.

To validate midwives' remarks relating to documentation of family history and consanguinity, a manual review of each hospital's maternity medical record was performed, documenting the presence of prompts regarding family history and consanguinity.

\section{Phase II}

A cross-sectional survey was administered to all members of the Victorian Branch of the Australian College of Midwives Incorporated (ACMI) via an anonymous questionnaire. The development of the questionnaire was informed by the findings of phase I, and validated for content and face validity. The questionnaire was then piloted by mail with 200 midwives randomly sampled from the ACMI database plus 28 midwives attending a seminar on prenatal testing. The final version of the questionnaire was sent to the remaining 533 members of the ACMI. As with the pilot questionnaire, a reminder was sent 1 month later. As there was no content change in the questionnaire between the pilot phase and the final version of the questionnaire, responses from the pilot have been included in the final analysis.

\section{Measures}

The final version of the questionnaire contained five sections: demographics, current practice, knowledge, attitudes, and educational preferences. Here we present only the results of the items relating to family history and consanguinity. Current practice: assessed by asking "As part of your role how often do you carry out specific tasks as part of clinical practice?" with a five point Likert scale ranging from 1 (never) to 5 (always), with the additional option of "not applicable." Referral practice: assessed by asking "For the following circumstances when would you refer to a clinical genetic service?" with yes, no and unsure options. Attitudes: assessed by rating level of importance of activities to clinical practice and confidence to carry out activities using a five-point Likert scale ranging from 1 (very unimportant/not at all confident) to 5 (very important/ very confident) respectively. Personal unease in carrying out activities: assessed by a binary scale (yes/no). Open-ended question invited participants to clarify their response to the attitude and personal unease questions.

\section{Data analysis}

Data from the questionnaires were coded and entered in STATA version 10, with a $20 \%$ data entry check. Descriptive statistics were used to describe the sample in demographic data and clinical practice activities relating to asking about a family history and consanguinity. The variables describing clinical practice were subsequently collapsed for further analysis and recorded as a binary variable (routine practice: "often" to "al- 
ways"; not routine practice: "never" to "sometimes"). Variables of importance and confidence were also collapsed into binary variables for subsequent analysis; (not important/not confident-Likert scale 1-3; important/confident-Likert scale $4-5)$. The variables describing referral practice were also collapsed into a binary variable to assess current intentions to refer (would refer: "yes," currently would not refer: "no and unsure"). Chi-squared analysis was performed to determine the associations between midwifery attributes and routine enquiry about family history and consanguinity, as well as referral practice of midwives. Variables included were selected based on our a priori hypotheses from phase I. All variables with an association of $P<0.1$ with the outcome variable were entered into a binary logistic regression model. Solicited comments relating to attitudes and personal unease were analyzed using content analysis. ${ }^{35}$

\section{RESULTS}

\section{Approach to family history collection}

Midwives' approach to family history collection was assessed through qualitative data analysis. Nine focus groups $(n=50)$ were conducted with qualified midwives $(n=46)$ and final year student midwives $(n=4)$. Qualified midwives had worked between 1 and 30 years, whereas student midwives had completed 29 weeks clinical placement within the public hospital system. Participants worked across the entire spectrum of midwifery care including prenatal clinical work, birthing suite and postnatal ward. Midwives who worked in tertiary and secondary level hospitals generally worked within one specific area, whereas midwives in primary level care worked across the range of midwifery areas.

Asking about a family history was part of standard midwifery care, occurring during the first clinical appointment:

"When our women come to book in we ask them a question on family history"

(Hospital G: secondary level regional hospital, no genetic clinic)
However, it was evident that midwives saw this as collecting only medical information about the family, as illustrated by comments such as:

“. . . we do ask if there's any medically ill babies on either side of the family and, you know, if there's learning difficulties, all those sort of things"

(Hospital D: tertiary level metropolitan hospital, genetic clinic in situ)

Discussion around family history was prompted by questions in the hospital maternity medical record. However, the specific information obtained about the family history varied between hospitals, and between midwives within each hospital (see Table 1). Midwives did not mention recording the information collected as a standard pedigree; they seem to document this information as written notes within the maternity medical record. If this information suggested a genetic risk, midwives typically referred to either a genetics team, if one was located in situ, or to the obstetric team.

$$
\begin{aligned}
& \text { “... we know when to refer; we may not know what it's about, } \\
& \text { but we know when to refer" }
\end{aligned}
$$

(Hospital C, tertiary level metropolitan hospital, genetic clinic in situ)

Only midwives at one center (hospital C) sought information on consanguinity, prompted by a reference in the maternity medical record. In a review of the maternity medical records from the seven participating hospitals, this was the only hospital medical record that contained a prompt for consanguinity although all had at least one prompt in relation to family history. Midwives from other hospitals did not voluntarily ask about consanguinity, instead only discussing the issue if the topic was raised by the patient.

Midwife 6: But I haven't come across [consanguinity]

Midwife 1: But we don't actually ask

Midwife 6: No we don't

Table 1

Factors that influence practice ${ }^{a}$

\begin{tabular}{lll}
\hline Practice & \multicolumn{1}{c}{ Promoting factor } & Inhibiting factor \\
\hline $\begin{array}{l}\text { Asking about a family } \\
\text { history }\end{array}$ & $\begin{array}{l}\text { Prompts in maternity medical record-specific questions to elucidate } \\
\text { family history often left to the discretion of individual midwife } \\
\text { "I specifically ask if they've had a family history of things like Down } \\
\text { syndrome ... born with abnormalities like blindness, deafness, spina } \\
\text { bifida and cleft lip"c }\end{array}$ & N/A \\
Asking about \\
$\begin{array}{l}\text { consanguinity } \\
\text { - Prompts in maternity medical record }\end{array}$ & $\begin{array}{l}\text { - Raised by couple } \\
\text { "do you ask that question? Unless they tell you, you wouldn't think to } \\
\text { ask that question"d }\end{array}$ & $\begin{array}{c}\text { Personal unease } \\
\text { "they'd probably get offended if you ask[ed] } \\
\text { that here" }\end{array}$ \\
\hline
\end{tabular}

${ }^{a}$ For the two areas examined, asking about a family history and asking about consanguinity, participants raised a number of factors that influenced their practice, either through promoting practice or inhibiting practice.

${ }^{b}$ Midwives did not raise any factors that inhibited taking a family history.

${ }^{c}$ Hospital A, secondary level metropolitan hospital, no genetics clinic.

${ }^{d}$ Hospital D, tertiary level metropolitan hospital, genetics clinic in situ.

${ }^{e}$ Hospital F, secondary level metropolitan hospital, no genetics clinic. 
(Hospital D, tertiary level metropolitan hospital, genetic clinic in situ)

Midwives equated the concept of consanguinity with cousin relationships, mainly referring to first-cousin unions when discussing their previous experiences in providing maternity care for consanguineous couples. However, many of these midwives expressed some personal unease in raising the issue of consanguinity, in particular how to broach the subject in a sensitive manner. Other midwives felt anxious about asking couples about what may be seen as a taboo subject (see Table 1). A small number of midwives also gave the impression that they were uncomfortable with the idea of sexual relationships between related individuals, such as cousins, using offensive language to describe the concept of consanguinity. A small number also referred to incestuous relationships, but only while joking about how they could ask a patient about consanguinity.

Midwife 4: But it doesn't always come up in your discussions antenatally

Midwife 1: Yeah, 'is he your brother' (laughing)

(Hospital F, secondary level maternity hospital, no genetics clinic)

\section{Midwives' behavior in collecting family history information}

To corroborate the findings from the qualitative data, questionnaires were sent to all Victorian members of ACMI. Of the 761 midwives who received a questionnaire, two were returned to sender and 21 participants deemed themselves ineligible to participate. Of the remaining 738 midwives, 335 (45.4\%) returned completed questionnaires. Out of these, two midwives provided an employer postcode not in Victoria, whereas another 16 indicated current job description outside of clinical practice. These 18 questionnaires were excluded from subsequent analysis, thus 317 questionnaires were analyzed. Characteristics of responders are shown in Table 2.

The quantitative survey data confirmed findings from phase I with $65.1 \%$ (95\% confidence interval (CI) $59.4-70.5 \%$ ) of midwives $(n=301)$ routinely asking about family history in clinical practice compared with only $6.4 \%$ (95\% CI $4-9.9 \%$ ) of midwives $(n=295)$ routinely asking about consanguinity. Midwives attached a higher level of importance to asking about family history in midwifery practice $(95.5 \%$ [95\% CI $92.5-$ 97.5\%]) than consanguinity (57.7\% [95\% CI 51.9-63.3\%]). Midwives also had more confidence in asking about family history $(72.7 \%$ [95\% CI $67.4-77.5 \%])$ than consanguinity (22.6\% [18-27.6\%]). Concurrent solicited comments indicate midwives correlate importance with: clinical relevance ("consanguinity is something I have never thought to discuss - need to know more about implications"); and significance to their patient population ("consanguinity not common in our area, haven't experienced this"). Midwives confidence was related to: personal knowledge; skills; and clinical experience ("we are not given any training on how to approach these issues [consanguinity] or even what to ask and why, so how can we be confident in this area"). Midwives show more personal unease
Table 2

Characteristics of midwives who completed questionnaire

\begin{tabular}{|c|c|c|}
\hline Characteristic & Category & $\begin{array}{c}\text { Number } \\
(\%)\end{array}$ \\
\hline \multirow[t]{5}{*}{ Age $(n=314)$} & $\leq 30 \mathrm{yrs}$ & $28(8.9)$ \\
\hline & $31-40$ yrs & $57(18.2)$ \\
\hline & $41-50$ yrs & $129(41.1)$ \\
\hline & $51-60$ yrs & $89(28.3)$ \\
\hline & $>60 \mathrm{yrs}$ & $11(3.5)$ \\
\hline \multirow[t]{5}{*}{ Classification $(\mathrm{n}=308)$} & $\begin{array}{l}\text { Students/first } \\
\text { year graduates }\end{array}$ & $27(8.8)$ \\
\hline & Grade 2 & $97(31.5)$ \\
\hline & $\mathrm{CMS} / \mathrm{CMC}^{a}$ & $83(26.9)$ \\
\hline & $\begin{array}{l}\text { Senior } \\
\quad \text { Practitioners }\end{array}$ & $79(25.7)$ \\
\hline & Other $^{b}$ & $22(7.1)$ \\
\hline \multirow[t]{3}{*}{ Length worked as midwife $(n=315)$} & $\leq 10 \mathrm{yrs}$ & $113(35.9)$ \\
\hline & $11-20 \mathrm{yrs}$ & $79(25.1)$ \\
\hline & $>20 \mathrm{yrs}$ & $123(39.0)$ \\
\hline \multirow[t]{2}{*}{ Type of midwifery training $(n=308)$} & Hospital-based & $195(63.3)$ \\
\hline & University-based & $113(36.7)$ \\
\hline \multirow[t]{2}{*}{ Employment status $^{c}(n=313)$} & Full-time & $61(19.5)$ \\
\hline & Part-time & $252(80.5)$ \\
\hline \multirow[t]{2}{*}{ Provide prenatal care $(n=317)$} & Yes & $152(47.9)$ \\
\hline & No & $165(52.1)$ \\
\hline \multirow[t]{2}{*}{ Location of hospital $^{d}(n=195)$} & Metropolitan & $96(49.2)$ \\
\hline & Regional & $99(50.8)$ \\
\hline \multirow[t]{2}{*}{ Type of hospital $(n=289)$} & Public & $250(86.5)$ \\
\hline & Private & $39(13.5)$ \\
\hline \multirow[t]{3}{*}{ Hospital level $(n=293)$} & Tertiary & $70(23.9)$ \\
\hline & Secondary & $180(61.4)$ \\
\hline & Primary & $43(14.7)$ \\
\hline
\end{tabular}

${ }^{a}$ Clinical midwife specialists/clinical midwife consultants.

${ }^{b}$ Included community midwife and midwife in independent practice.

${ }^{c}$ Participants were asked to provide the number of hours they work per fortnight. By Australian convention midwives who work $80+$ hours/fortnight are classified as full-time employees, with midwives who work less than 80 hours/ fortnight classified as part-time employees.

${ }^{d}$ Participants were asked to provide postcode for hospital address. These were then classified as metropolitan or regional by cross-referencing postcodes with the Department of Human Services Classification of maternity hospital location (http://www.health.vic.gov.au/maternity/).

around asking about consanguinity $(40.1 \% \quad[95 \%$ CI $34.6-45.8])$ than family history (2.3\% [95\% CI $1-4.5 \%])$, and indicate that this unease is due to the perceived sensitive nature of the subject ("couples may be offended suggesting they are related!! Difficult situation").

\section{Factors associated with asking about family history}

The results of the univariate analysis are shown in Table $3 \mathrm{a}$. Variables significantly associated with midwives asking about 
Table 3a

Factors associated with midwives' asking about family history as part of routine practice

\begin{tabular}{|c|c|c|c|c|c|}
\hline Variable & Category & $\begin{array}{l}\text { Total number in } \\
\text { category } \mathrm{N}(\%)\end{array}$ & $\begin{array}{c}\text { Number in category } \\
\text { that ask about } \\
\text { family history } \\
\text { routinely } \mathrm{N}(\%)\end{array}$ & $\chi^{2}$ & $P$ \\
\hline \multirow[t]{2}{*}{ Importance to clinical practice } & Important & 281 (95.3) & $188(66.9)$ & 5.7 & 0.022 \\
\hline & Not important & $14(4.7)$ & $5(35.7)$ & & \\
\hline \multirow[t]{2}{*}{ Confidence } & Confident & $218(73.6)$ & $153(70.2)$ & 9.1 & 0.003 \\
\hline & Not confident & $78(26.4)$ & $40(51.3)$ & & \\
\hline \multirow[t]{2}{*}{ Personal unease } & Yes & $7(2.4)$ & $4(57.1)$ & 0.2 & 0.70 \\
\hline & No & $288(97.6)$ & $188(65.3)$ & & \\
\hline \multirow[t]{2}{*}{ Provide prenatal care } & Yes & $148(49.2)$ & $114(77)$ & 18.2 & $<0.001$ \\
\hline & No & $153(50.8)$ & $82(53.6)$ & & \\
\hline \multirow[t]{2}{*}{ Work in tertiary level hospital } & Yes & $67(34.8)$ & $44(65.7)$ & 0.03 & 0.88 \\
\hline & No & $212(65.5)$ & $137(64.6)$ & & \\
\hline \multirow[t]{2}{*}{ Type of midwifery training } & University-based & $107(36.5)$ & $67(62.6)$ & 0.4 & 0.54 \\
\hline & Hospital-based & $186(63.5)$ & $123(66.1)$ & & \\
\hline
\end{tabular}

Table 3b

Logistic regression of predictors of midwives' asking about family history as part of routine practice $(\mathrm{n}=295)^{a}$

\begin{tabular}{lccc}
\hline Variable & $\mathrm{OR}^{b}$ & $(95 \% \mathrm{CI})$ & $P$ \\
\hline $\begin{array}{l}\text { Important to clinical } \\
\text { practice }\end{array}$ & 3.4 & $(1.1-11.1)$ & 0.039 \\
Confident & 1.7 & $(1.0-3.0)$ & 0.069 \\
Provided prenatal care & 2.6 & $(1.5-4.3)$ & $<0.001$ \\
\hline
\end{tabular}

${ }^{a}$ Twenty-two participants were excluded because they had missing values for at least one item.

${ }^{b} \mathrm{OR}=$ odds ration from logistic regression model.

family history were: perceived clinical importance $\left(\chi^{2}[\mathrm{df}, 1]=\right.$ 5.7, $P=0.022)$; confidence in asking about family history $\left(\chi^{2}[\mathrm{df}, 1]=9.1, P=0.003\right)$; and providing prenatal care $\left(\chi^{2}[\mathrm{df}, 1]=18.2, P<0.001\right)$. Table $3 \mathrm{~b}$ shows the logistic regression model for asking about family history in clinical practice. The results show that midwives who feel that asking about family history is important to clinical practice (adjusted odds ratio $[\mathrm{OR}]=3.4[95 \% \mathrm{CI} 1.1-11.1], P=0.039)$ and midwives who work in a prenatal clinic (adjusted OR $=2.60[95 \% \mathrm{CI}$ $1.5-4.3], P<0.001$ ) are more likely to collect family history information routinely. Although univariate analysis showed self-rated confidence in asking about family history was a predictor for routine collection of family history, the effect of this variable was removed when we adjust for whether the midwife worked in a prenatal clinic, and hence is not an independent predictor.

\section{Factors associated with asking about consanguinity}

The results of the univariate analysis are shown in Table 4a. Variables significantly associated with midwives' asking about consanguinity were: perceived clinical importance $\left(\chi^{2}[\mathrm{df}, 1]=\right.$
$8.5, P=0.004)$; confidence in asking about consanguinity $\left(\chi^{2}(\mathrm{df}, 1)=30.0, P<0.001\right)$; personal unease in asking about consanguinity $\left(\chi^{2}(\mathrm{df}, 1)=7.6, P=0.006\right)$; providing prenatal care $\left(\chi^{2}(\mathrm{df}, 1)=4.6, P=0.032\right)$; and working in a teritary level hospital $\left(\chi^{2}(\mathrm{df}, 1)=5.3, P=0.047\right)$. Table $4 \mathrm{~b}$ shows the logistic regression model for asking about consanguinity. The results show that midwives who are confident in asking about consanguinity (adjusted OR $=5.3$ [95\% CI 1.3-22.1], $P=$ 0.023 ) are more likely to ask about consanguinity. Although univariate analysis showed midwives' perception of clinical importance and personal unease were predictors for asking about consanguinity, the effect of these variables was removed when adjusted for midwives' self-rated confidence, and hence they are not independent predictors.

\section{Midwives attitudes toward referral for genetic counseling}

Although the identification of consanguineous couples is not occurring systematically in practice, the qualitative data suggested that if couples disclose that they are consanguineous, midwives would refer them for genetic counseling. This was supported by the quantitative data with midwives reporting that they would refer to a genetic service when there was an indication of consanguinity ( $73 \%$ of responders $(95 \%$ CI $67.6-77.9), n=307$ ). The results of the bivariate analysis are shown in Table 5a. Variables significantly associated with midwives' intention to refer for consanguinity were: perceived clinical importance in asking about consanguinity $\left(\chi^{2}(\mathrm{df}, 1)=\right.$ $8.1, P=0.005)$; and personal unease in asking about consanguinity $\left(\chi^{2}(\mathrm{df}, 1)=6.3, P=0.012\right)$. A trend was also observed between midwives' confidence in asking about consanguinity and their intention to refer for consanguinity $\left(\chi^{2}(\mathrm{df}, 1)=3.0\right.$, $P=0.085)$. Table $5 \mathrm{~b}$ shows the logistic regression model for midwives' intent to refer for consanguinity. The results show 
Table 4a

Factors associated with midwives' asking about consanguinity as part of routine practice

\begin{tabular}{|c|c|c|c|c|c|}
\hline Variable & Category & $\begin{array}{l}\text { Total number in } \\
\text { category N (\%) }\end{array}$ & $\begin{array}{l}\text { Number in category } \\
\text { that ask about } \\
\text { consanguinity } \\
\text { routinely } \mathrm{N}(\%)\end{array}$ & $\chi^{2}$ & $P$ \\
\hline \multirow[t]{2}{*}{ Importance to clinical practice } & Important & $165(57.5)$ & $17(10.3)$ & 8.5 & 0.004 \\
\hline & Not important & $122(42.5)$ & $2(1.6)$ & & \\
\hline \multirow[t]{2}{*}{ Confidence } & Confident & $66(22.8)$ & $14(21.2)$ & 30.0 & $<0.001$ \\
\hline & Not confident & $224(77.2)$ & $5(2.2)$ & & \\
\hline \multirow[t]{2}{*}{ Personal unease } & Yes & $117(40.6)$ & $2(1.7)$ & 7.6 & 0.006 \\
\hline & No & $171(59.4)$ & $17(9.9)$ & & \\
\hline \multirow[t]{2}{*}{ Provide prenatal care } & Yes & $147(49.8)$ & $14(9.5)$ & 4.6 & 0.032 \\
\hline & No & $148(50.2)$ & $5(3.4)$ & & \\
\hline \multirow[t]{2}{*}{ Work in tertiary level hospital } & Yes & $66(24.3)$ & $7(10.6)$ & 5.3 & 0.047 \\
\hline & No & $206(75.7)$ & $7(3.4)$ & & \\
\hline \multirow[t]{2}{*}{ Type of midwifery training } & University-based & $107(37.4)$ & $7(6.5)$ & 0.003 & 0.96 \\
\hline & Hospital-based & $179(62.6)$ & $12(6.7)$ & & \\
\hline
\end{tabular}

Table 4b

Logistic regression of predictors of midwives' asking about consanguinity as part of routine practice $(\mathrm{n}=263)^{a}$

\begin{tabular}{lccc}
\hline Variable & $\mathrm{OR}^{b}$ & $(95 \% \mathrm{CI})$ & $P$ \\
\hline Important to clinical practice & 6.4 & $(0.8-52.8)$ & 0.085 \\
Confident & 5.3 & $(1.3-22.1)$ & 0.023 \\
Personal unease & 0.8 & $(0.2-4.8)$ & 0.78 \\
Provided prenatal care & 2.3 & $(0.6-8.0)$ & 0.20 \\
Worked in tertiary level hospital & 2.1 & $(0.6-6.8)$ & 0.22 \\
\hline
\end{tabular}

${ }^{a}$ Fifty-four participants were excluded because they had missing values for at least one item.

${ }^{b} \mathrm{OR}=$ odds ration from logistic regression model.

that midwives who perceive it is of clinical importance to ask about consanguinity (adjusted OR $=1.9[95 \%$ CI 1.1-3.2] $P=$ 0.029 ) are more likely to refer consanguineous couples for genetic counseling. Although the bivariate analysis showed midwives' personal unease in asking about consanguinity was a predictor for midwives' intent to refer for consanguinity, the effect of this variable disappeared when we adjusted for perceived clinical importance, and hence is not an independent predictor. There was no relationship between midwives' clinical practice in asking about consanguinity and their intention to refer a consanguineous couple $\left(\chi^{2}[\mathrm{df}, 1]=0.43, P=0.51\right.$ ). This suggests midwives believe consanguinity is a trigger for referral to a genetic service, regardless of whether they actually collect this information in their clinical practice.

\section{DISCUSSION}

The patient pathway to access genetic information begins with identification of genetic risk factors, then referral. Ideally primary care practitioners would begin genetic risk assessment with a series of screening questions, ${ }^{1}$ which in the prenatal setting would include a family history of pregnancy loss, congenital abnormalities, intellectual disability, hearing loss, and consanguinity. ${ }^{12}$ The presence of one of these should result in either collection of a more extensive family history or, due to time or knowledge constraints, referral for pedigree assessment. ${ }^{37}$ Midwives report that genetic risk assessment occurs through a series of questions about family history, which are limited to medical information about the family, followed by referral for genetic assessment if indicated.

\section{Current practice and barriers}

Midwives report that they commonly collected medical family history, but the content of this is variable. Focus group data suggest best practice occurred when family history collection was prompted by specific questions within the maternity medical record, but in many cases midwives have to rely on personal judgment to determine what information is relevant. This may result in failure to identify significant information for risk assessment. ${ }^{2}$ However, despite this variability in collection, when an indication of genetic risk was identified midwives knew to refer for genetic counseling.

One such indication of genetic risk is consanguinity. Both qualitive and quantitative data analysis demonstrate that the majority of midwives were aware that consanguinity is a trigger for referral to a genetic service. Despite this awareness, information about consanguinity was generally not collected. Midwives rely on their patients to bring up the issue of consanguinity, as they are reluctant to raise the issue themselves. This failure to routinely ask about consanguinity is in large part due to midwives' attitudes. Some midwives do not believe that they need to ask about consanguinity in their practice: either they 
Table 5a

Factors associated with midwives' intent to refer for consanguinity

\begin{tabular}{|c|c|c|c|c|c|}
\hline Variable & Category & $\begin{array}{c}\text { Total number } \\
\text { in category } \\
\mathrm{N}(\%)\end{array}$ & $\begin{array}{l}\text { Number in category } \\
\text { with intention to } \\
\text { refer for } \\
\text { consanguinity } \\
\mathrm{N}(\%)\end{array}$ & $\chi^{2}$ & $P$ \\
\hline \multirow{2}{*}{$\begin{array}{l}\text { Ask about consanguinity as part of } \\
\text { clinical practice }\end{array}$} & Routine & $19(6.6)$ & $15(79)$ & 0.43 & 0.51 \\
\hline & Not routine & $268(93.4)$ & $193(72)$ & & \\
\hline \multirow[t]{2}{*}{ Importance to clinical practice } & Important & $170(57.3)$ & $136(80)$ & 8.1 & 0.005 \\
\hline & Not important & $127(42.7)$ & $83(65.4)$ & & \\
\hline \multirow[t]{2}{*}{ Confidence to ask } & Confident & $69(22.9)$ & $56(81.2)$ & 3 & 0.085 \\
\hline & Not confident & $232(77.1)$ & $164(70.7)$ & & \\
\hline \multirow[t]{2}{*}{ Personal unease in asking } & Yes & $121(40.2)$ & $79(65.3)$ & 6.3 & 0.012 \\
\hline & No & $180(59.8)$ & $141(78.3)$ & & \\
\hline \multirow[t]{2}{*}{ Provide prenatal care } & Yes & $150(48.9)$ & $110(73.3)$ & 0.02 & 0.89 \\
\hline & No & $157(51.1)$ & $114(72.6)$ & & \\
\hline \multirow[t]{2}{*}{ Work in tertiary level hospital } & Yes & $67(23.7)$ & $53(79.1)$ & 2.0 & 0.16 \\
\hline & No & $216(76.3)$ & $152(70.4)$ & & \\
\hline \multirow[t]{2}{*}{ Type of midwifery training } & University-based & $111(37.2)$ & $82(73.9)$ & 0.05 & 0.83 \\
\hline & Hospital-based & $187(62.8)$ & $137(72.7)$ & & \\
\hline
\end{tabular}

Table 5b

Logistic regression of predictors of midwives' intent to refer for consanguinity $(\mathrm{n}=296)^{a}$

\begin{tabular}{lccc}
\hline Variable & $\mathrm{OR}^{b}$ & $(95 \% \mathrm{CI})$ & $P$ \\
\hline Asking is important to clinical practice & 1.9 & $(1.1-3.2)$ & 0.029 \\
Confident to ask & 1.2 & $(0.6-2.4)$ & 0.67 \\
Personal unease in asking & 0.7 & $(0.4-1.2)$ & 0.18 \\
\hline
\end{tabular}

${ }^{a}$ Twenty-one participants were excluded because they had missing values for at least one item.

${ }^{b} \mathrm{OR}=$ odds ration from logistic regression model.

assume that consanguinity is not relevant to their patient population or that asking about consanguinity would not alter their clinical management. Other reasons why midwives don't ask about consanguinity is their lack of confidence and personal unease in broaching the subject: these two factors are not independent. The qualitative data suggest these midwives were worried about offending their patients-implying consanguineous relationships are socially unacceptable. A minority of midwives also used offensive language when describing consanguineous unions. Western society often portrays consanguineous unions as distasteful, ${ }^{38}$ and health practitioners are not immune to societal views.

\section{Overcoming the barriers: the theory of planned behavior}

Although individual hospitals and health systems need to decide whether to incorporate consanguinity in pregnancy assessment, those that do so will need to address the barriers identified. A potential way to overcome these barriers and consequently change clinical behavior, is to apply a change theory: the theory of planned behavior, ${ }^{39}$ which has been employed in the engagement of nurses and midwives in genetics education. ${ }^{40}$ The theory proposes that the intent to adopt behavior, such as specific clinical practice, stems from three factors: attitude, subjective norms, and perceived behavioral control. ${ }^{39}$ Figure 1 provides a representation of the behavior under question, asking about consanguinity. The attitudes required to promote intention are individual's positive or negative views about the behavior, and an internal assessment of the outcomes and benefits of adopting the behavior. For example, midwives may weigh up what information they could gain from asking about consanguinity and whether this information would impact on the clinical care of their patient. The subjective norm is how much the individual is influenced by social pressure to adopt the behavior. In this case the midwife would be influenced by the hospital's expectation that the issue of consanguinity is raised, through the inclusion of prompts within maternity medical records (see Fig. 1). Finally, perceived behavioral controls relate to how difficult the individual considers adopting the behavior to be, i.e., how "do-able" is it to ask about consanguinity. As described here, perceived behavioral control incorporates both confidence and overcoming any personal trepidation in asking about consanguinity.

This framework suggests a two-pronged approach for behavioral change: education and minor organizational change. Formal education can target midwives' attitudes about the clinical relevance of consanguinity and increase personal con- 


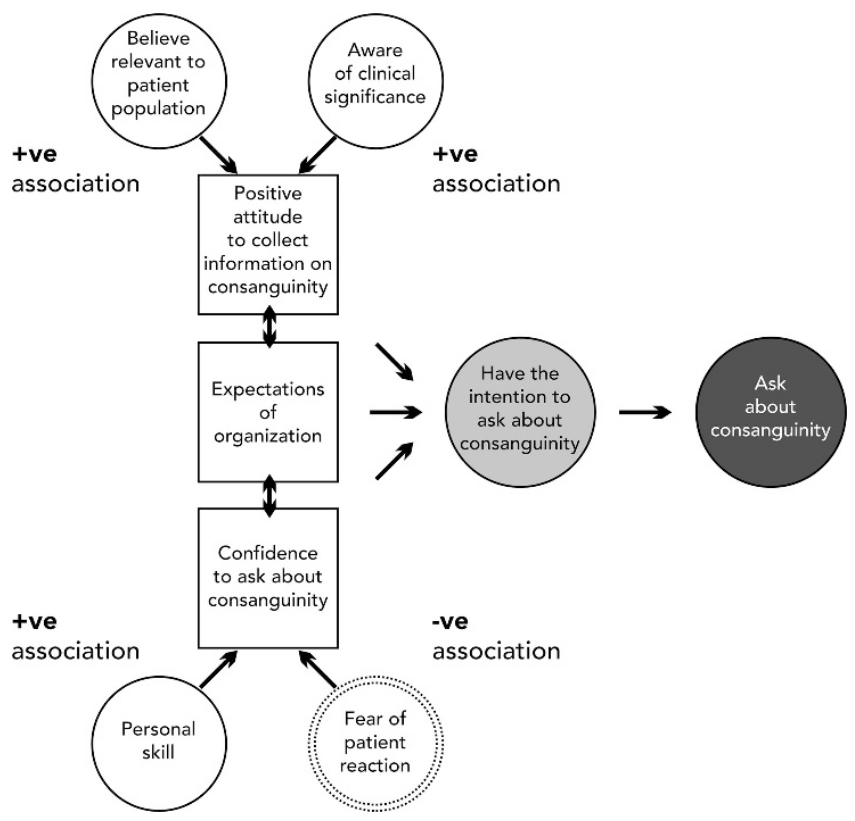

Fig. 1. Asking about consanguinity in clinical practice.

fidence through enhancing skills. This approach has long been advocated as a means to improve clinical confidence within a primary care setting,,$^{1,41}$ and could be applied in both preregistration training programs and postregistration professional development. A minor organizational change can support formal education by including a prompt about consanguinity in maternity medical records to make hospital expectations about family history risk assessment clear. Incorporating a question about consanguinity in this way may also over come any unease midwives feel in discussing this subject. Precedence for this exists in midwifery practice, where anxiety about domestic violence screening has been overcome by routinely asking all patients about domestic violence. ${ }^{42,43}$

\section{Study limitations}

Although the qualitative findings are not intended to represent the views of the general midwifery populations, they do provide an insight into the midwifery practice of the participants and of their hospitals. A more representative view was obtained through the quantitative arm of the project. A sample of practising midwives could only be achieved through the ACMI database, a society with voluntary membership. However, our responder characteristics are comparable to the general midwifery population in Victoria, ${ }^{44}$ apart from location of employment and age distribution. Midwives who responded to this survey were, on average, older. However, the most recent statistics reported for the midwifery population in Victoria were collected in $1999,{ }^{44}$ so our findings may reflect opinions that the midwifery population is an ageing population..$^{45}$ We also had a higher proportion of responders from regional Victoria. Our response rate is similar to other studies in genetics which use self-administered questionnaires with primary care practitioners. ${ }^{13,46}$ As with all studies, there is the potential for response bias, although family history collection was comparable with that reported by other primary care physicians such as general practitioners and family physicians..$^{9,13,41}$

\section{CONCLUSION}

With globalization and increasing migration, populations are becoming more heterogeneous. These changes will influence genetic risk assessment, particularly in the prenatal period. Policy makers state the importance of including consanguinity as a core component of family history assessment in the prenatal period, ${ }^{6,7}$ yet our study, the first to examine this particular clinical practice, shows this is not part of organizational or midwifery practice in our setting. We suggest a two-pronged approach to promote inclusion of consanguinity as part of family history collection: (1) educational strategies can be employed to induce a paradigm shift in the conventional views about family history to include consanguinity in risk assessment, and (2) the use of a standard prompt in hospital maternity medical records and family history tools to increase documentation regarding consanguinity. Directing these initiatives across the primary care spectrum will enhance identification of consanguineous couples during pregnancy permitting accurate assessment and enable access to appropriate genetic counseling and testing.

\section{ACKNOWLEDGMENTS}

This work was supported by Murdoch Childrens Research Institute, Internal Grant. Michelle Bishop supported by $\mathrm{Na}$ tional Health and Medical Research Council Public Health Postgraduate Scholarship (334389). We gratefully acknowledge Yasmin Bylstra for assistance with data collection, Dr. Veronica Collins for statistical advice, and Dr. Fiona Cullinane for methodological and recruitment advice.

\section{References}

1. Rich EC, Burke W, Heaton C, et al. Reconsidering the family history in primary care. J Gen Intern Med 2004;19:273-280.

2. Wolpert C, Speer M. Harnessing the power of the pedigree. J Midwifery Womens Health 2005;50:189-196.

3. Guttmacher AE, Collins F, Carmona RH. The family history-more important than ever. N Engl J Med 2004;351:2333-2336.

4. Beery TA, Shooner KA. Family history: the first genetic screen. Nurse Pract 2004;29: 14-25.

5. Hayflick SJ, Eiff MP. Role of primary care providers in the delivery of genetics services. Community Genet 1998;1:18-22.

6. American Medical Association prenatal screening questionnaire. Available at http://ama-assn.org/ama/pub/category/13332.html. Accessed June 4, 2007.

7. March of Dimes Birth Defects Foundation preconception/prenatal family history questionnaire. Available at: http://www.marchofdimes.com/gyponline. Accessed September 21, 2007.

8. Wolpert CM. Surgeon General launches new public health campaign: the family history initiative. JAAPA 2005;18:20-22.

9. Summerton N, Garrood PVA. The family history in family practice: a questionnaire study. Fam Pract 1997;14:285-288.

10. Acheson L, Wiesner G, Zyzanski SJ, Goodwin M, Stange KC. Family history-taking in community family practice: implications for genetic screening. Genet Med 2000; 2:180-185.

11. Rose P, Humm E, Hey K, Jones L, Huson SM. Family history taking and genetic counselling in primary care. Fam Pract 1999;16:78-83.

12. Bennett R. The practical guide to the genetic family history, 1st ed. New York: Wiley-Liss, 1999:38-67. 


\section{Bishop et al.}

13. Hayflick SJ, Eiff MP, Carpenter L, Steinberger J. Primary care physicians' utilization and perceptions of genetics services. Genet Med 1998;1:13-21.

14. NHS Sickle Cell and Thalassaemia Screening Programme. Standards for the linked antenatal and newborn screening programme, 1st ed: NHS Antenatal and Newborn Screening Programmes, 2006.

15. Bittles A. Consanguinity and its relevance to clinical genetics. Clin Genet 2001;60: 89-98.

16. Bennett R, Motulsky A, Bittles A, et al. Genetic counseling and screening of consanguineous couple and their offspring: recommendations of the National Society of Genetic Counselors. J Genet Couns 2002;11:97-119.

17. Yunis K, Mumtaz G, Bitar F, et al. Consanguineous marriage and congenital heart defects: a case-control study in the neonatal period. Am J Med Genet A 2006;140: $1524-1530$.

18. Stoltenberg C, Magnus P, Lie RT, Daltveit AK, Irgens LM. Birth defects and parental consanguinity in Norway. Am J Epidemiol 1997;145:439-448.

19. Mumtaz G, Tamin H, Kanaan M, et al. Effect of consanguinity on birth weight for gestational age in a developing country. Am J Epidemiol 2007;165:742-752.

20. Tamim H, Khogali M, Beydoun H, Melki I, Yunis K. National Collaborative Perinatal Neonatal Network. Consanguinity and apnea of prematurity. Am J Epidemiol 2003;158:942-946.

21. Bundey S, Alam H, Kaur A, Mir S, Lancashire RJ. Race, consanguinity and social features in Birmingham babies: a basis for a prospective study. J Epidemiol Community Health 1990;44:130-135.

22. Mokhtar M, Abdel-Fattah MM. Consanguinity and advanced maternal age as risk factors for reproductive losses in Alexandria, Egypt. Eur J Epidemiol 2001;17:559565.

23. Grant JC, Bittles A. The comparative role of consanguinity in infant and childhood mortality in Pakistan. Ann Hum Genet 1997;61:143-149.

24. Stoll C, Alembik Y, Dott B, Feingold J. Parental consanguinity as a cause of increased incidence of birth defects in a study of 131,760 consecutive births. Am J Med Genet 1994;49:114-117.

25. Hussain R. The impact of consanguinity and inbreeding on perinatal mortality in Karachi, Pakistan. Paediatr Perinat Epidemiol 1998;12:370-382.

26. Modell B, Darr A. Genetic counselling and customary consanguineous marriage. Nat Rev Genet 2002;3:225-229.

27. Mitford J. The American way of birth, 1st ed. New York: Dutton, 1992:165-242.

28. Lavender T, Chapple J. An exploration of midwives' views of the current system of maternity care in England. Midwifery 2004;20:324-334.

29. Brown S, Davey MA, Bruinsma F. Women's views and experiences of postnatal hospital care in the Victorian Survey of Recent Mothers 2000. Midwifery 2005;21: $109-126$.

30. Holland M, Holland E. Survey of connecticut nurse-midwives. J Midwifery Womens Health 2007;52:106-115.

31. Department of Human Services. Future directions for Victoria's maternity services Melbourne Victoria: Victorian Government Department of Human Services, 2004

32. Devane D, Murphy-Lawless J, Begley C. Childbirth policies and practices in Ireland and the journey towards midwifery-led care. Midwifery 2007;23:92-101

33. Lazarus J, Rull K, Huws D, Rasch V, Liljestrand J. A survey of midwives' views on providing aspects of antenatal care in Estonia. Midwifery. 2007; in press.

34. Riley M, Davey MA, King J. Births in Victoria 2003-2004. Victorian Perinatal Data Collection Unit. Melbourne: Victorian Government of Human Services, 2005.

35. Liamputtong P, Ezzy D. Qualitative research methods, 2nd ed. Melbourne: Oxford University Press, 2005;75-99:259-261.

36. Glasser BG, Strauss AL. The Discovery of grounded theory — strategies for qualitative research, 1st ed. New York: Aldine De Gruyter, 1967:101-115.

37. Gaff CL. Identifying clients who might benefit from genetic services and information. Nurs Stand 2005;20:49-53.

38. Ottenheimer M. Forbidden relatives, the American myth of cousin marriage. Cham paign, IL: University of Illinois Press, 1996.

39. Ajzen I. The theory of planned behavior. Organ Behav Hum Decis Process 1991;50: $179-211$.

40. Kirk M, Tonkin E, Burke S. Engaging nurses in genetics: the strategic approach of the NHS National Genetics Education and Development Centre. J Genet Couns 2008; 17:180-188

41. Metcalfe S, Seipolt M, Aitken M, Flouris A. Educating general practitioners about prenatal testing: approaches and challenges. Prenat Diag 2005;25:592-601.

42. Price SM, Baird K, Salmon D. Asking the question: antenatal domestic violence. Prac Midwife 2005;8:21-25.

43. Edin KE, Hogberg U. Violence against pregnant women will remain hidden as long as no direct questions are asked. Midwifery 2002;18:268-278.

44. Australian Health Workforce Advisory Committee. The midwifery workforce in Australia. AHWAC Report 2002.2, Sydney 2002:38-46.

45. Tracy S, Barclay L, Brodie P. Contemporary issues in the workforce and education of Australian midwives. Aust Health Rev 2000;23:78-88.

46. Metcalfe A, Haydon J, Bennett C, Farndon P. Midwives' views of the importance of genetics and their confidence with genetic activities in clinical practice: implications for the delivery of genetics education. J Clin Nurs 2007;17:519-530. 